\title{
ENHANCEMENT OF LIFE TIME OF THE DIMENSIONALLY STABLE ANODE FOR COPPER ELECTROPLATING APPLICATIONS
}

\begin{abstract}
In order to enhance the long-term stability of DSA for copper electroplating process, in the present study, noble metal oxides with excellent electrochemical properties was used and optimum condition was determined the ratio of noble metal oxides, surface pre-treatment of titanium substrate and heat treatment. The effect of the surface pretreatment of titanium substrate and ratio of noble metal oxides were estimated by accelerated test at the highly current density conditions. The lifetime of DSA increase six-fold higher as the oxide thickness of Ta 7 : Ir 3 composition ratio. Under the optimal condition, surface pretreatment led to dramatic increase in the lifetime of DSA.
\end{abstract}

Keywords: Dimensionally Stable Anode, Surface treatment, Life time, Copper, Electrodeposition

\section{Introduction}

Recently, dimensionally stable anode (DSA) for electrochemical reaction is used in various electric industries such as electroplating, non-degradable wastewater treatment, seawater purification, catalyst electrode of fuel cell [1]. The electrodeposited copper foil process was reduction copper from electrolyte using DSA and titanium plate cathode. High current is applied in this process, copper is deposited at a high rate on the cathode, and oxygen evolution reaction increased in the anode. Increasing oxygen reaction was facilitated degradation on the surface of anode, corresponding increase applied voltage and power consumption. Therefore, the long-term stability of DSA is the most important property for electrodeposition of copper thin film. DSAs were fabricated two or three components metal oxide such as iridium, ruthenium, tantalum and platinum because of their electrochemical performance and stability. It was generally known that electrochemical performance and life time of the DSA could be determined by the electrode production method such as the pre-treatment of titanium surface, coating thickness, optimal composition of novel metal oxide and heat treatment [2-4].

Surface etching of titanium plate by acid solution leads to remove oxide layer and surface roughening, which is ascribed to an increase in interfacial bonding between coating layer and substrate due to an increase in the surface contact area [5]. The thick coating layer was reduced heat of reaction during electrochemical reaction at high current condition. The high heat of reaction for DSA is delaminated the interface between novel coating layer and titanium substrate. The fabricated DSA by thermal decomposition at high temperature were existed mud crack structure. The electrolyte penetrates into the inner surface (grain boundary and cracks) of electrodes during the electrolysis, leading to an increase in active site for oxygen evolution. Degradation mechanism of the Ti / Ir-Ta oxide anodes has been proposed by degradation of Ti/oxide coating layer interface resulting from the dissolution and anodic oxidation of metal base alternatively [6,7]. In order to enhance the long-term stability of DSA for copper electroplating process, in the present study, noble metal oxides with excellent electrochemical properties was used and optimum condition was determined the ratio of noble metal oxides and surface pre-treatment of titanium substrate. The composition and surface morphologies on the surface of DSA were characterized by field emission scanning electron microscopy (FE-SEM), energy dispersive X-ray spectrometer (EDS or EDX). The effect of the surface pretreatment of titanium substrate and ratio of noble metal oxides were estimated by accelerated test at the highly current density conditions.

\section{Experimental}

The pure titanium plate substrates were sand blasted using alumina powder, degreased and then the surface oxides were removed in oxalic acid solution. Novel metal such as iridium, ruthenium, tantalum and platinum in a different composition ratio were coated using $\mathrm{IrCl}_{3} \cdot \mathrm{H}_{2} \mathrm{O}, \mathrm{RuCl}_{3} \cdot \mathrm{H}_{2} \mathrm{O}, \mathrm{TaCl}_{5}$ and $\mathrm{PtCl}_{3}$. The coating solutions were dissolved in isopropyl alcohol with novel metal chloride which was stirred for adequate mixing. Various

\footnotetext{
SURFACE TREATMENT R\&D GROUP, KOREA INSTITUTE OF INDUSTRIAL TECHNOLOGY, INCHEON, KOREA

** DEPARTMENT OF ADVANCED MATERIAL SCIENCE AND ENGINEERING, MOKPO NATIONAL UNIVERSITY, CHONNAM, KOREA

\# Corresponding author: shson@kitech.re.k
} 
metal oxide composition of DSA were obtained by brushing the coating solution on titanium plate, dried in air oven at $423 \mathrm{~K}$ for 30 minutes. The brushing process was repeated for 5 times or 10 times, and then thermal decomposed in furnace at atmospheric pressure and $823 \mathrm{~K}$ for 30 minute. The titanium plate substrate was treated by anodizing process, and then removing anodizing layer in order to nano-dimple titanium surface. The anodizing process was operated that the applied consistent potential was $50 \sim 80 \mathrm{~V}$ in a mixture electrolyte of ethylene glycol, $0.1 \sim 0.5$ wt. $\%$ ammonium fluoride and $0.5 \sim 5$ wt. $\%$ deionized water at the temperature of $298 \mathrm{~K}$. And then anodizing layer was removed in oxalic acid in order to improve surface conductivity of titanium substrate. To evaluation the durability of various metal contained DSA, accelerated life testing was performed that agitation of the solution was possible in a mixed solution of $1.2 \mathrm{M}$ sulfuric acid and organic additive at temperature of $323 \mathrm{~K}$ by circulatory system. The immersed surface of anode and cathode plate was $2 \mathrm{~cm} \times 2 \mathrm{~cm}$, applied current density of $1,000 \mathrm{~A} / \mathrm{cm}^{2}$. The Titanium plate for cathode was polished with $\# 180, \# 320, \# 600, \# 800$ and \#1,200 grit $\mathrm{SiC}$ abrasive paper in order to electrodeposited copper easily was removed in copper foil manufacturing process.

\section{Results and discussion}

The concentrations of mixed metal oxide anodes were analyzed using Energy-dispersive X-ray spectroscopy (EDS) as shown in Table 1 . The metal oxide containing mainly Iridium, Ruthenium, Tantalum and Platinum of the respective one and two components were prepared. It can be detected that metal composition ratios are about 7:3.

The effects of metal composition ratio were estimated by accelerated test at the highly current density conditions. Figure 1 shows the change of durability of DSA with different metal composition. In generally electroplating process, operating potential range is constant but the degradation on the surface of DSA, corresponding increase applied voltage. For each anode, an abrupt potential increase was assumed failure lifetime of DSA. The DSA coting composition of Ir 7 : Ta 3, Ta $7:$ Ir 3 and Pt has the longlist accelerated life time. It has been reported that the DSA composition Ir and Ta improves the life time of the DSA due to the mud crack morphology [2]. Figure 2 shows the effect of metal oxide thickness of the Ta $7:$ Ir 3 ratio coating layer. The thermal decomposition was repeated five cycle and ten cycle,
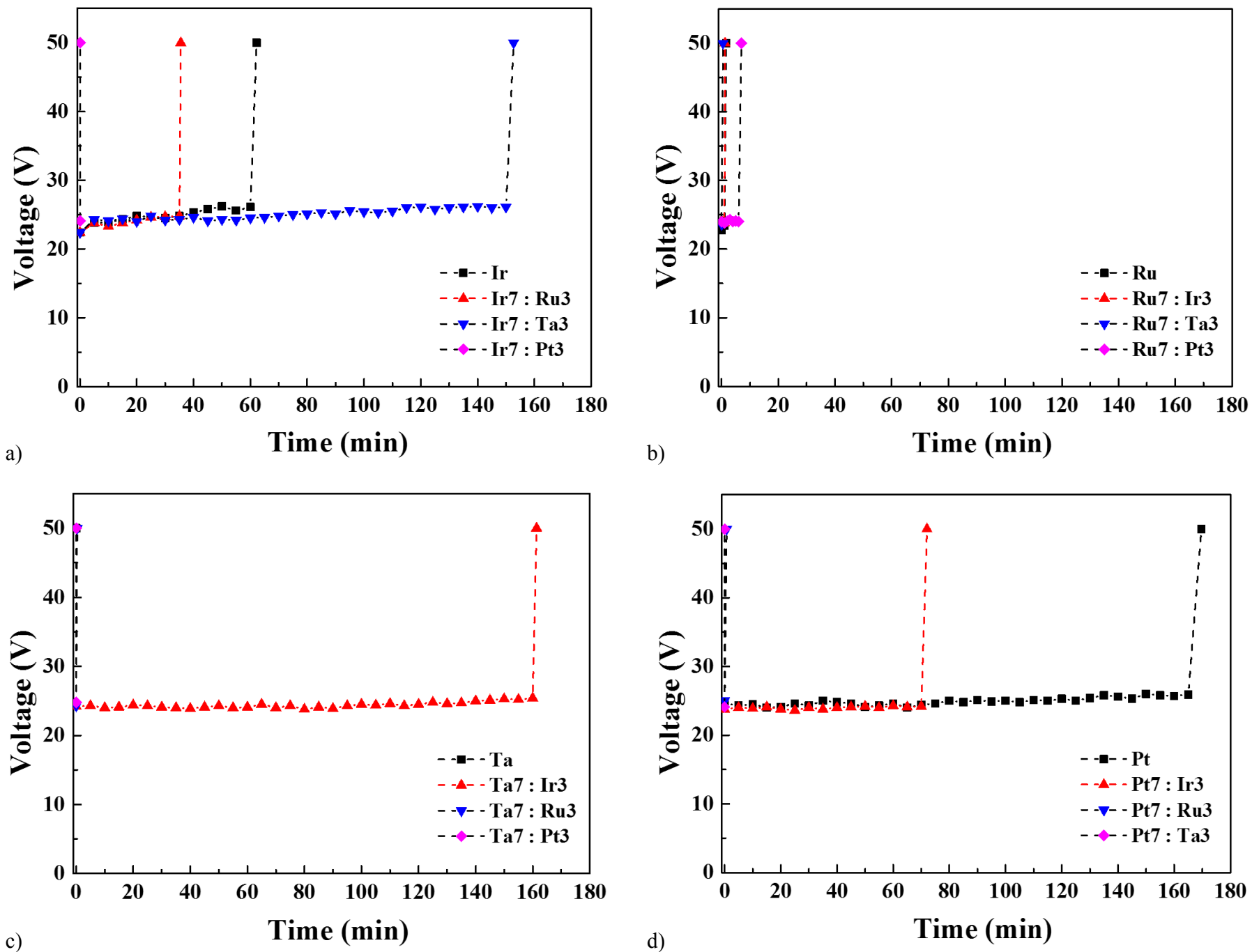

Fig. 1. Voltage-time graph in accelerated life test for different of metal composition of (a) Iridium group DSA, (b) Ruthenium group DSA, (c) Tantalum group DSA and (d) Platinum group DSA 
TABLE 1

Quantitative analysis of metal concentration in DSA by EDS

\begin{tabular}{|c|c|c|c|c|}
\hline \multirow{2}{*}{$\begin{array}{c}\text { Metal } \\
\text { composition of DSA }\end{array}$} & \multicolumn{4}{|c|}{ Concentration (wt.\%) } \\
\hline & Ir & Ru & Ta & Pt \\
\hline $\mathrm{Ir}$ & 100 & & & \\
\hline Ir $7:$ Ru 3 & 68.23 & 31.77 & & \\
\hline Ir $7:$ Ta 3 & 66.87 & & 33.13 & \\
\hline Ir $7:$ Pt 3 & 70.27 & & & 29.73 \\
\hline $\mathrm{Ru}$ & & 100 & & \\
\hline Ru $7:$ Ir 3 & 28.39 & 71.61 & & \\
\hline $\mathrm{Ru} 7: \mathrm{Ta} 3$ & & 68.88 & 31.12 & \\
\hline $\mathrm{Ru} 7:$ Pt 3 & & 73.35 & & 26.65 \\
\hline $\mathrm{Ta}$ & & & 100 & \\
\hline Ta $7: \operatorname{Ir} 3$ & 26.24 & & 73.76 & \\
\hline Ta $7: \mathrm{Ru} 3$ & & 29.90 & 70.10 & \\
\hline Ta $7:$ Pt 3 & & & 70.28 & 29.72 \\
\hline $\mathrm{Pt}$ & & & & 100 \\
\hline Pt $7:$ Ir 3 & 28.14 & & & 71.86 \\
\hline $\mathrm{Pt} 7: \mathrm{Ru} 3$ & & 26.37 & & 73.63 \\
\hline Pt $7:$ Ta 3 & & & 30.05 & 69.05 \\
\hline
\end{tabular}

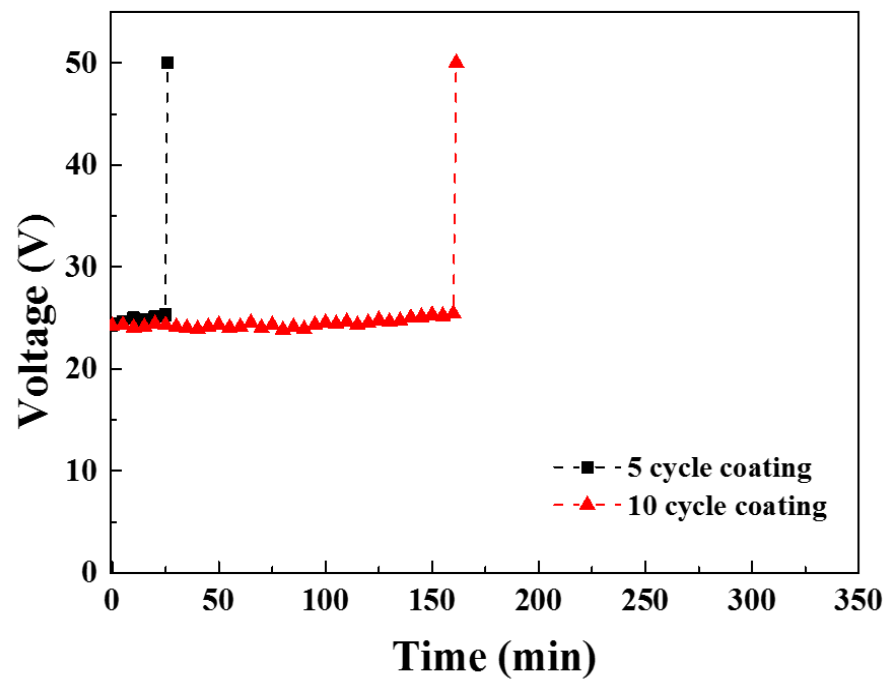

Fig. 2. Voltage-time graph in accelerated life test for Ta $7:$ Ir 3 ratio electrode prepared by brushing with (a) 5 cycle coating and (b) 10 cycle coating
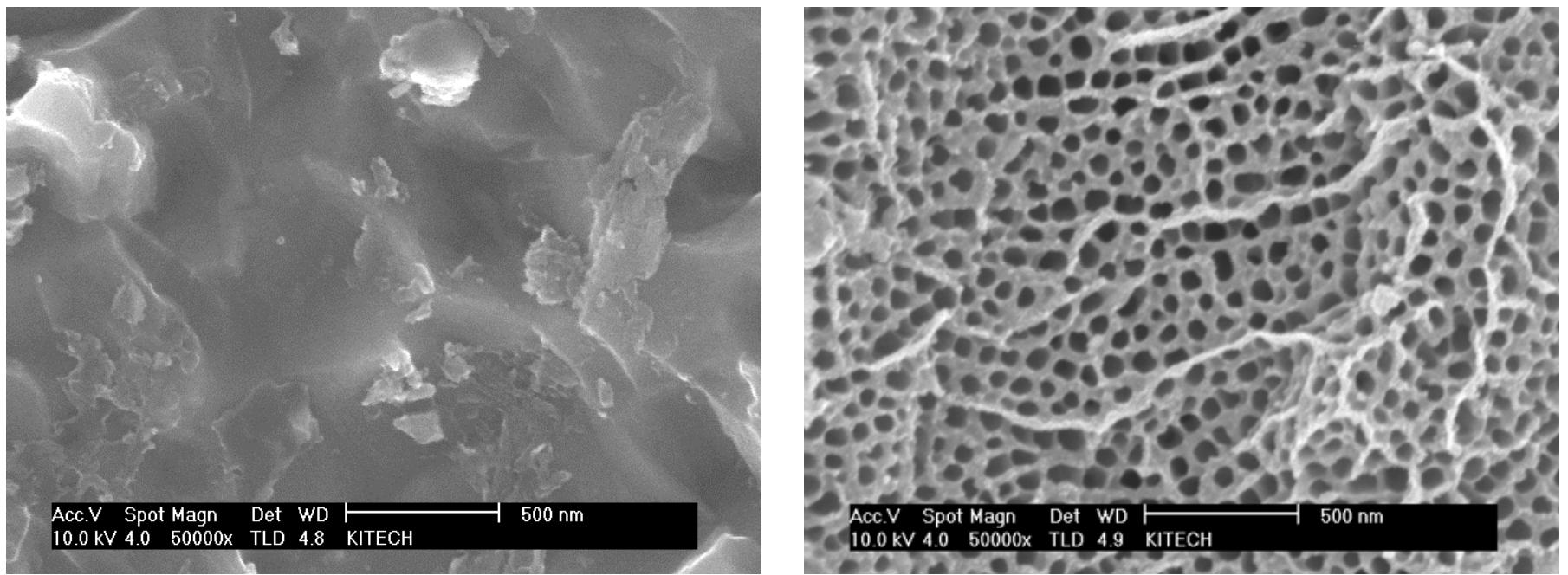

a)

b)

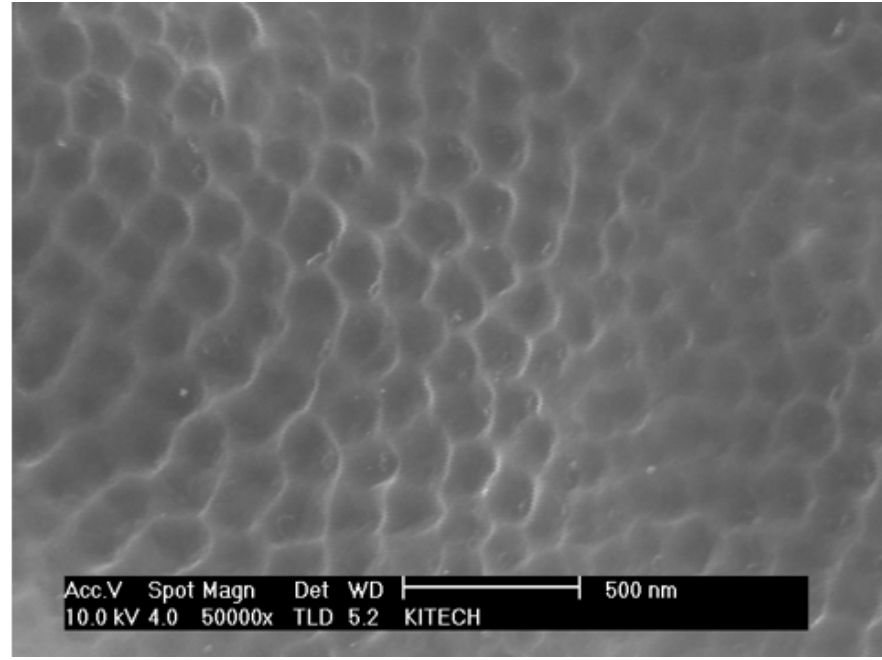

c)

Fig. 3. FE-SEM images of surface morphologies on the titanium substrate; (a) without treatment, (b) nanoporous anodic oxidation treatment and (c) oxidation removing treatment 
respectively, which were confirmed as $3 \mu \mathrm{m}$, and $7 \mu \mathrm{m}$, thick, to achieve the comparative thickness of oxides. Increased oxide thickness led to a six-fold increase in the lifetime of DSA. The nano-dimple of titanium treatment were optimized in order to increase the durability of DSA. The surface morphologies on the titanium substrate by FE-SEM as shown in Fig. 3. Without nanodimple of titanium treatment, surface show a smooth and clean morphology. Thin nano-porous layer was produced by titanium anodizing treatment and then, anodizing layer was removed in oxalic acid. The effect of surface roughness of nano-dimple layer was investigated using AFM. Roughness values of Ra were obtained $1.0683 \mu \mathrm{m}$ and $1.5437 \mu \mathrm{m}$ for without and with nanodimple of titanium treatment, respectively, pre-treatment causes a slight increase in roughness. To investigate the mechanism involved in the improvement in adhesion due to pretreatment, the mechanical interlocking effect due to the increase in surface roughness was first characterized [8]. The effect of nano-dimple of titanium treatment on the accelerated life test of DSA was investigated as shown Fig. 4. The nano-dimple of titanium treatment led to a thirteen-fold increase in the lifetime of DSA. Nano-dimple of titanium treatment leads to surface roughening, which is ascribed to an increase in adhesion between metal oxide layer and substrate due to an increase in the surface contact area and the mechanical interlocking effect. The improvement of accelerated life time of DSA seems to be closely related to adhesion between metal oxide coating layer and substrate.

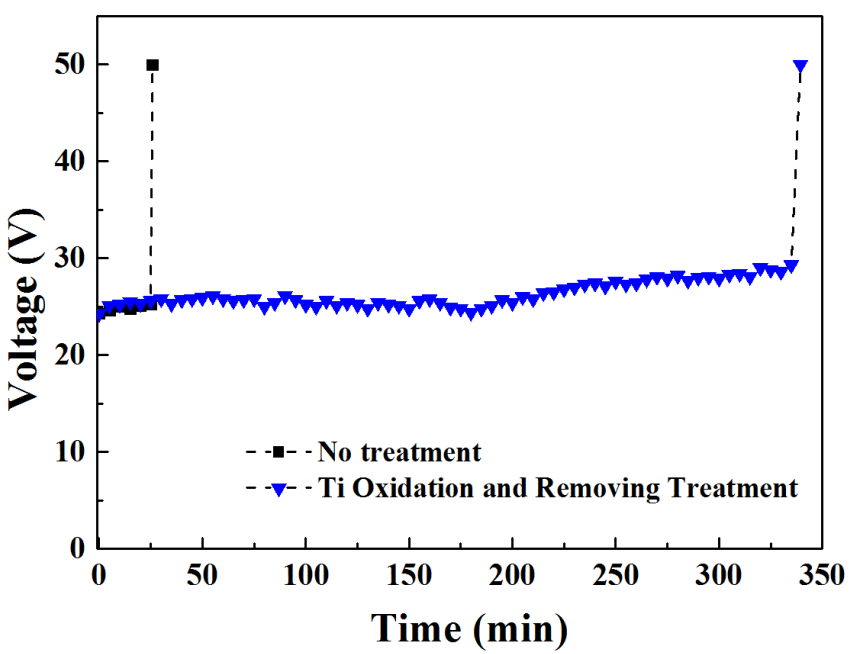

Fig. 4. Voltage-time graph in accelerated life test for Ta $7:$ Ir 3 ratio electrode (a) without treatment and (b) Titanium oxidation and removing treatment

\section{Conclusions}

We were obtained the follows through the DSA manufactured by nano-dimple of titanium treatment. Various metal oxide composition of DSA were optimized by brushing the coating solution on titanium plate, drying in air at $423 \mathrm{~K}$ for 30 minutes. Nano-dimple of titanium treatment led to surface of nano structure, which is ascribed to an increase a thirteen-fold increase in the lifetime of DSA. The improvement of accelerated life time of DSA seems to be closely related to adhesion between metal oxide coating layer and substrate.

\section{Acknowledgments}

This work was supported by the Technology Innovation Program (10043789, Development of manufacturing process of electrodeposit copper foils for LIBs and PCBs, with $700 \mathrm{MPa}$ tensile strength and 3\% elongation to overcome winding limits) funded by the Ministry of Trade, industry \& Energy (MI, Korea).

\section{REFERENCES}

[1] A.N.S. Rao, V.T. Venkatarangaiah, Environ. Sci. Pollut. Res. 21, 3197 (2014).

[2] Z. Yan, Y. Zhao, Z. Zhang, G. Li, H. Li, J. Wang, Z. Feng, M. Tang, X. Yuan, R. Zhang, Y. Du, Electrochimica Acta. 157, 345 (2015).

[3] P. Bagri, Evaluation of coated titanium anode. Master thesis, University of Utah, Utah, UT 84112, August (2012).

[4] J.Y. Lee, D.K. Kang, K.H. Lee, D.Y. Chang, Mater. Sci. Appl. 2, 237 (2011).

[5] S.Y. Kwak, H.G. Kim, J.M. Byun, J.H. Park, M.-J. Suk, S.-T. Oh, Y.D. Kim, J. Kor. J. Kor. Powd. Met. Inst. 21, 28 (2014).

[6] J.M. Hu, H.M. Meng, J.Q. Zhang, C.N. Cao, Corr. Sci. 44, 1655 (2002).

[7] F. Fathollahi, M. Javanbakht, M.R. Ganjali, P. Nourozi, Anal. Bioanal. Electrochem, 5, 689 (2013).

[8] S.C. Park, Y.B. Park, J. Electron. Mater. 37, 1565 (2008). 